\title{
The association between arterial stiffness and tongue manifestations of blood stasis in patients with type 2 diabetes
}

Po-Chi Hsu ${ }^{1,2}$, Yu-Chuen Huang ${ }^{3,4^{*}}$, John Y. Chiang ${ }^{5,6}$, Hen-Hong Chang ${ }^{3,7}$, Pei-Yung Liao ${ }^{8^{*}}$ and Lun-Chien Lo ${ }^{2,9^{*}}$

\begin{abstract}
Background: Diabetes mellitus (DM) is a hypercoagulable state and is associated with highly increased risk of vascular complications. In the theory of traditional Chinese medicine (TCM), these vascular complications are classified as blood stasis. Diagnosis of the tongue plays an important role in TCM; a bluish tongue, petechiae, and engorged sublingual collateral vessels are manifestations of blood stasis. This study aimed to characterize the tongue manifestations of blood stasis and derive a relationship between blood stasis and vascular disorders in patients with type $2 \mathrm{DM}$.
\end{abstract}

Method: We conducted a cross-sectional study of 140 patients with type 2 DM, and compared demography, laboratory, physical examination, ankle brachial index(ABI), brachial-ankle pulse wave velocity (ba-PWV), and tongue manifestation datas. An automatic tongue diagnosis system was used to capture tongue images and characterize clinical tongue manifestations.

Results: A bluish or petechiae tongue was assoicated with a significant decrease in high-density lipoprotein level, and bluish tongue was associated with significant increase in blood triglyceride in patients with type $2 \mathrm{DM}$. On assessing arterial stiffness, patients with a petechiae tongue had a higher ba-PWV for both sides (L:1938.41 \pm 469 . $54 \mathrm{~cm} / \mathrm{sec}$ v.s. $1723.99 \pm 302.16, p=0.02 ;$ R:1937.28 \pm 405.55 v.s.1741.99 $\pm 325.82, p=0.03)$.

Conclusion: Blood stasis, particularly a tongue with petechiae, may be associated with arterial stiffness in patients with type $2 \mathrm{DM}$. Furthermore, tongue diagnosis could detect blood stasis relevant to DM and could serve as a feasible predictor for DM.

Keywords: Traditional Chinese medicine (TCM), Diabetes mellitus (DM), Tongue diagnosis, Blood stasis, Arterial stiffness,and brachial-ankle pulse wave velocity (ba-PWV)

Abbreviations: $\mathrm{ABI}$, Ankle brachial index; $\mathrm{AC}$ sugar, Fasting blood-glucose level; baPWV, Brachial-ankle pulse wave velocity; BMI, Body mass index; CCH, Changhua Christian Hospital; $\mathrm{Cr}$, Creatinine; GOT, Glutamate oxaloacetate transaminase; GPT, Glutamate pyruvate transaminase; HbA1c, Hemoglobin A1c; HDL, High-density lipoprotein; LDL, Low-density lipoprotein; TCM, Traditional Chinese medicine; TG, Triglyceride

\footnotetext{
* Correspondence: yuchuen@mail.cmu.edu.tw; 48795@cch.org.tw; 126478@cch.org.tw

${ }^{3}$ School of Chinese Medicine, China Medical University, No. 91, Hsueh-Shih Rd., Taichung, Taiwan

${ }^{8}$ Department of Endocrinology, Changhua Christian Hospital, No.135 Nanxiao St., Changhua, Taiwan

2Department of Chinese Medicine, Changhua Christian Hospital, No.135

Nanxiao St., Changhua, Taiwan

Full list of author information is available at the end of the article
} 


\section{Background}

As the global population increases and ages, diabetes mellitus (DM) has become a major public health concern worldwide [1-3]. DM increases the risk for disability and premature death, and imparts a substantial socioeconomic burden due to the micro- and macro-vascular complications [3]. The long-term micro-vascular complications of DM include retinopathy [4], nephropathy, neuropathy and macro-vascular complications. DM is a hypercoagulable state and is associated with an increased risk of ischemic events; it is also associated with accelerated atherothrombosis $[5,6]$. Arterial stiffness is closely related to the progression of DM complications [7]. Consequently, patients with DM have shown a 2- to 4-fold greater risk for coronary artery disease and cerebrovascular disease than those without DM [8]. Thus, vascular complications and arterial stiffness due to poor blood circulation should be closely monitored in patients with DM.

Blood stasis is one of the most important pathological concepts in traditional Chinese medicine (TCM) [9]. Blood stasis is characterized as a disorder of blood circulation with hallmarks including extravagated or sluggish blood circulation and viscous or congested blood; all of these hallmarks may contribute to various disease pathologies [10]. Many diseases lead to blood stasis, such as cardiovascular disease, cerebral vascular accidents, and DM [11]. Blood stasis is often accompanied by characteristic symptoms, such as pain in a fixed position, a dark-purple colored face, infraorbital darkness, a bluish tongue, an engorged sublingual varicosis, petechiae tongue, or an astringent pulse [12].

Tongue diagnosis is important in TCM [13]. The tongue is connected to the internal organs through the meridians; thus the conditions of the organs, qi, blood, and bodily fluids, as well as the degree and progression of disease, are manifested in the tongue [14]. Clinically, practitioners observe tongue characteristics, such as tongue color and shape, fur color and thickness, and the amount of saliva, to deduce the primary ailment of a patient [15]. A bluish tongue, petechiae and engorged sublingual collateral vessels are potential tongue manifestations of blood stasis [16]. Tongue diagnosis is helpful in detecting blood stasis of rheumatoid arthritis (RA) and could serve as a feasible predictor of RA [17].

However, to the best of our knowledge, no study has focused on tongue diagnosis in patients with type $2 \mathrm{DM}$, despite the theoretical and clinical applications. This study aimed to investigate the tongue characteristics of and relationship between blood stasis and vascular disorders in patients with type $2 \mathrm{DM}$.

\section{Methods}

\section{Patients}

We conducted across-sectional study and recruited patients with type 2 DM from the Department of Chinese
Medicine, Changhua Christian Hospital, between January 2012 and December 2013. We excluded patients with type $1 \mathrm{DM}$ or type $2 \mathrm{DM}$ who had cancer. One hundred and forty eligible patients with type $2 \mathrm{DM}$ were enrolled. The purpose, procedures, potential risks, and benefits of the study were thoroughly explained to the patients. The personal details and photographs of the patients were kept confidential, and all participants signed consent for publication. This study was approved by the Institutional Review Board of Changhua Christian Hospital (IRB\#:111106).

\section{Data collection}

Patient metadata were collected (i.e., sex, age, weight, height, history of DM, and any micro-vascular complications). Physical examinations included blood pressure, body mass index(BMI), waistline, hipline, foot examination, ankle brachial index (ABI), and brachial-ankle pulse wave velocity (ba-PWV). Ba-PWV is a direct measurement of aortic stiffness and is the gold standard of arterial stiffness measurements [18]. ABI is a non-invasive method that assesses the patency of peripheral occlusive arterial disease [19]. Routine biological blood tests included hemoglobin A1c (HbA1c), fasting blood-glucose level, cholesterol, triglyceride (TG), high-density lipoprotein (HDL), low-density lipoprotein (LDL), creatinine $(\mathrm{Cr})$, glutamate oxaloacetate transaminase (GOT) and glutamate pyruvate transaminase (GPT) levels.

\section{Tongue photographs and procedures}

An automatic tongue diagnosis system was developed to capture tongue images. The consistency and stability of image capturing relies on the brightness and color calibration to compensate for variations, such as intensity and color temperature of light source as well as imaging hardware $[15,16]$. Analysis of tongue images was conducted by Chinese medical physicians who had 3-5 years of clinical experience in the Chinese medicine department of Changhua Christian Hospital (CCH), Taiwan. The physicians attended regularly meetings over the past two years and examined over 1000 tongue images from $\mathrm{CCH}$ outpatients. Tongue images were identified according to nine primary tongue features: tongue body shape (i.e., small, median, enlarged), tongue body color (i.e., pale, pink red, red), tongue characteristics (i.e., spots, petechiae, teethmarks, fissures), bluish tongue (i.e., yes, no), fur color (i.e., white, yellow), fur thickness (i.e., peeled, thin, thick), saliva (i.e., dry mouth, normal, wet mouth), and sublingual collateral vessels (i.e., normal, engorged) [15]. Tongue diagnosis followed a standardized protocol (Fig. 1).

\section{Data analysis}

The statistical analysis of datawas performed with IBM SPSS Statistics 19 (IBM Co., New York, NC, USA). After determining if that data was normal (Kolmogorov-Smirnov 


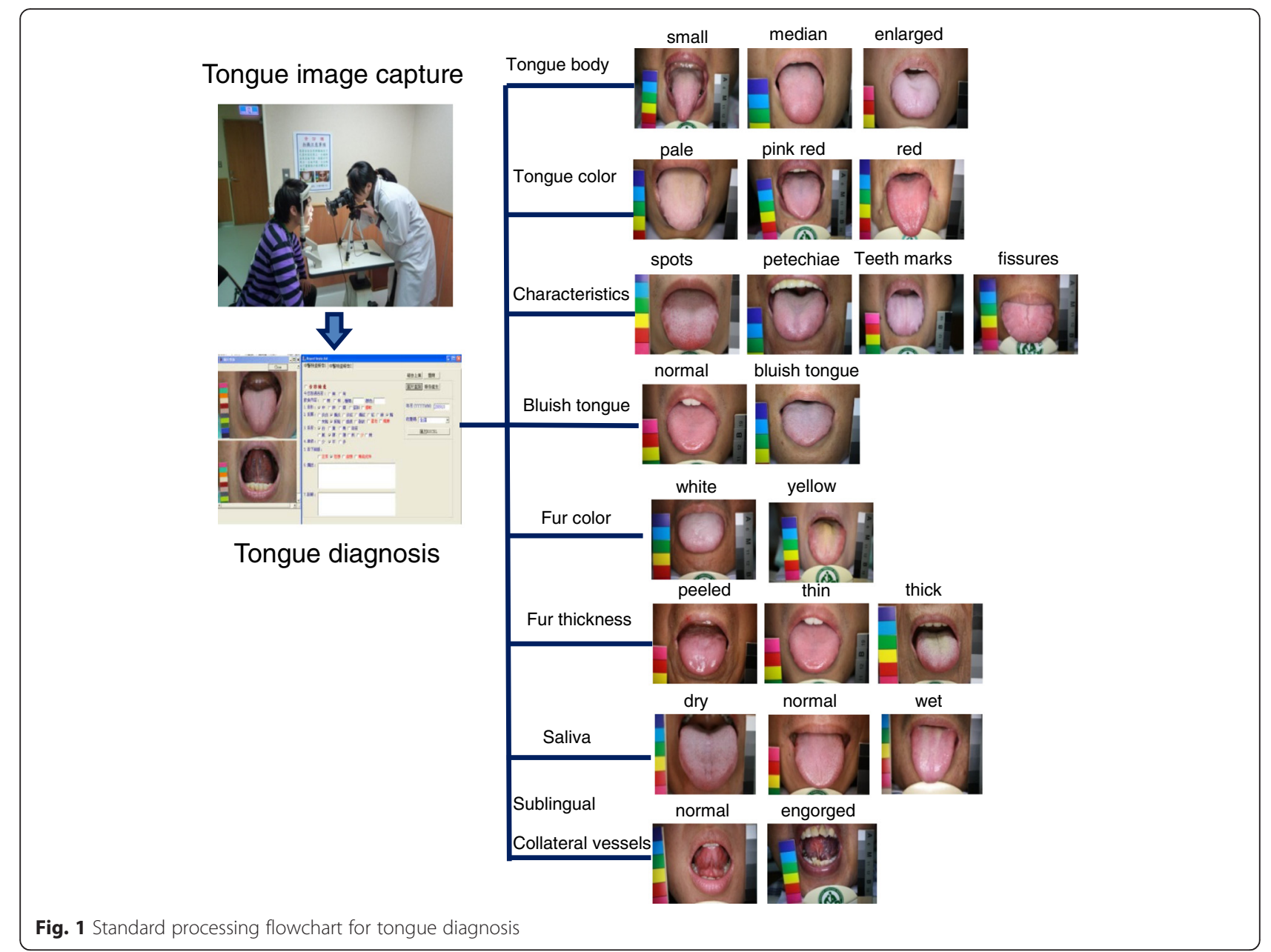

test), Student's $t$ tests were used to determine differences between continuous variables. Regression models were used to analyze the relationship between the change in baPWV and patients possessing tongue manifestations of blood stasis. A $p$-value less than 0.05 was considered statistically significant.

\section{Result}

The characteristics of the 140 patients with type $2 \mathrm{DM}$ were $40 \%$ males (56 patients) and $60 \%$ females ( 84 patients), the average age was $62.95 \pm 11.10$ years old (range of 33 to 87 years); the mean BMI was $25.94 \pm 3.93 \mathrm{~kg} / \mathrm{m}^{2}$, and mean HbA1C was $7.03 \pm 1.08 \%$ (Table 1). The duration of DM course in the patients was 2 to 35 years, with an average of $13.57 \pm 8.54$ years. Twenty-eight $(20.0 \%)$ of study patientshad retinopathy; fifty patients (35.7\%) had nephropathy and seventeen patinets $(12.1 \%)$ had neuropathy.

Tongue inspection refers to the visual examination of tongue body shape, tongue color, fur color, and fur thickness, as well as other characteristics. The tongue body shape was classified as median $(n=123,87.9 \%)$, enlarged
Table 1 Characteristics of 140 patients with type 2 diabetes

\begin{tabular}{ll}
\hline Characteristics & \\
\hline Age (years, mean \pm SD) & $62.95 \pm 11.10$ \\
Gender & $(56,40.0 \%)$ \\
$\quad$ Male $(n, \%)$ & $(84,60.0 \%)$ \\
Female $(n, \%)$ & $25.94 \pm 3.93$ \\
BMI (kg/m ${ }^{2}$, mean \pm SD) & $13.57 \pm 8.54$ \\
DM history (years, mean \pm SD) & $(39,38.6 \%)$ \\
$\leq 10$ years $(n, \%)$ & $(42,41.6 \%)$ \\
$10<$ age $\leq 20$ years $(n, \%)$ & $(20,19.8 \%)$ \\
$>20$ years $(n, \%)$ & $7.03 \pm 1.08$ \\
HbA1c (mean \pm SD) & $(72,54.6 \%)$ \\
$\leq 7$ ( $n, \%)$ & $(42,31.8 \%)$ \\
$7<$ HbA1c $\leq 8(n, \%)$ & $(18,13.6 \%)$ \\
$>8(n, \%)$ & \\
Micro-vascular complication & \\
Retinopathy $(n, \%)$ & $(28,20.0 \%)$ \\
Nephropathy $(n, \%)$ & $(50,35.7 \%)$ \\
Neuropathy $(n, \%)$ & $(17,12.1 \%)$ \\
\hline
\end{tabular}


Table 2 Tongue manifestations of patients with type 2 diabetes

\begin{tabular}{|c|c|c|}
\hline Tongue manifestations & Types & $N(\%)$ \\
\hline \multirow[t]{3}{*}{ Tongue body } & median & $123(87.9 \%)$ \\
\hline & enlarged & $15(10.7 \%)$ \\
\hline & small & $2(2.4 \%)$ \\
\hline \multirow[t]{3}{*}{ Body color } & pink red & $86(65.2 \%)$ \\
\hline & red & $31(23.5 \%)$ \\
\hline & pale & $15(11.4 \%)$ \\
\hline \multirow[t]{4}{*}{ Tongue characteristics } & spots & $32(22.9 \%)$ \\
\hline & petechiae & $22(15.7 \%)$ \\
\hline & teeth-marks & $80(57.1 \%)$ \\
\hline & fissures & $33(23.6 \%)$ \\
\hline \multirow[t]{2}{*}{ Bluish tongue } & no & $106(75.7 \%)$ \\
\hline & yes & $34(24.3 \%)$ \\
\hline \multirow[t]{2}{*}{ Fur color } & white & $97(73.5 \%)$ \\
\hline & yellow & $35(26.5 \%)$ \\
\hline \multirow[t]{3}{*}{ Fur thickness } & thin & $64(47.1 \%)$ \\
\hline & thick & $64(47.1 \%)$ \\
\hline & peeled & $8(5.9 \%)$ \\
\hline \multirow[t]{3}{*}{ Saliva } & normal & $110(80.9 \%)$ \\
\hline & dry mouth & $20(14.7 \%)$ \\
\hline & wet mouth & $6(4.4 \%)$ \\
\hline \multirow[t]{2}{*}{ Sublingual collateral vessels } & engorged & 99 (73.3 \%) \\
\hline & normal & $36(26.7 \%)$ \\
\hline
\end{tabular}

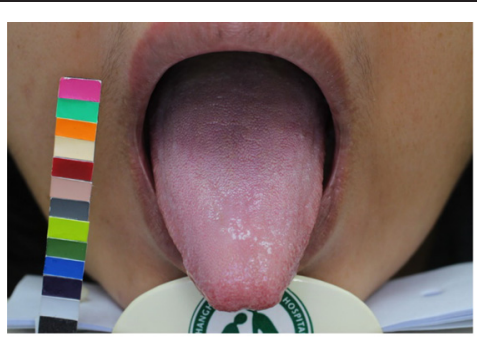

(a)

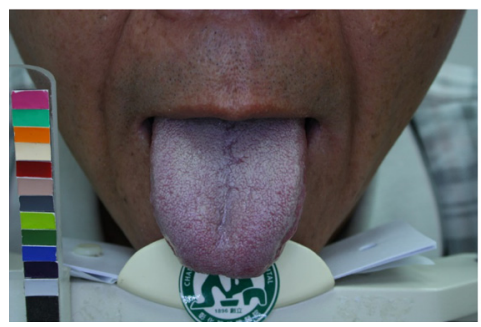

(c)
( $n=15,10.7 \%)$, and small $(n=2,2.4 \%)$ (Table 2). The tongue body color was pink red $(n=86,65.2 \%)$, red $(n=31,23.5 \%)$, or pale $(n=15,11.4 \%)$. Other characteristics observed on the tongue surface included teeth-marks $(n=80,57.1 \%)$, fissures $(n=33,23.6 \%)$, spots $(n=32,22.9 \%)$ and petechiae $(n=22,15.7 \%)$. A bluish toned tongue may indicate a problem with blood circulation $(n=34,24.3 \%)$. The classifications of fur color and thickness were white $(n=97,73.5 \%)$ or yellow $(n=35$, $26.5 \%)$ and thin fur $(n=64,47.1 \%)$, thick fur $(n=64$, $47.1 \%)$, or peeled fur $(n=8,5.9 \%)$, respectively. The amount of saliva observed was normal ( $n=110,80.9 \%)$, dry $(n=20,14.7 \%)$, or wet $(n=6,4.4 \%)$. There were 99 patients (73.3\%) with engorged sublingual collateral vessels.

According to the TCM theory, a bluish tongue, petechiae, and engorged sublingual collateral vessels are potential manifestations of blood stasis (Fig. 2). Therefore, the physical examinations and laboratory data were further examined to address the relationship between vascular disorders and blood stasis related to tongue characteristics (i.e., bluish tongue, petechiae, or engorged sublingual collateral vessels; Table 3). A bluish tongue was correlated with significant decrease in HDL $(p=0.03)$ and a significant increase in TG $(p=0.04)$ in the lipid profile (Table 3). Interestingly, both the left- and right-side ba-PWV (L: $1938.41 \pm 469.54 \mathrm{~cm} / \mathrm{sec}$ v.s. $1723.99 \pm$ $302.16 \mathrm{~cm} / \mathrm{sec}, p=0.02$; R: $1937.28 \pm 405.55 \mathrm{~cm} / \mathrm{sec}$ v.s. $1741.99 \pm 325.82 \mathrm{~cm} / \mathrm{sec}, p=0.03$ ) were significantly higher in patients with a petechiae tongue than in patients with type 2 DM.

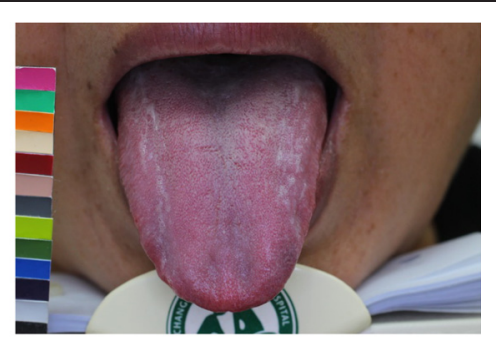

(b)

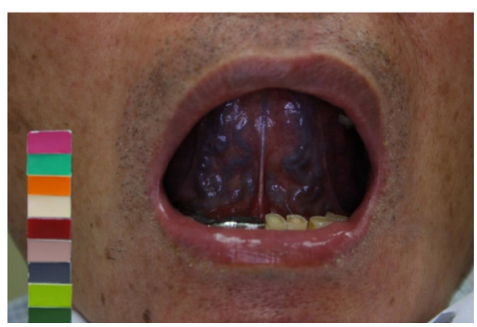

(d)

Fig. 2 Representative images of tongue manifestations: (a) normal tongue; (b) petechiae tongue; (c) bluish tongue, and; (d) engorged sublingual collateral vessels 
Table 3 Comparison of physical examinations and laboratory data of patients with type 2 diabetes with and without tongue manifestations of blood stasis

\begin{tabular}{|c|c|c|c|c|c|c|c|c|c|}
\hline \multirow[t]{2}{*}{ Variables } & \multicolumn{2}{|l|}{ Bluish tongue } & \multirow[t]{2}{*}{$p$-value } & \multicolumn{2}{|l|}{ Petechiae } & \multirow[t]{2}{*}{$p$-value } & \multicolumn{2}{|c|}{ Engorged sublingual collateral vessels } & \multirow[t]{2}{*}{$p$-value } \\
\hline & Without $(n=106)$ & With $(n=34)$ & & Without $(n=118)$ & With $(n=22)$ & & Without $(n=36)$ & With $(n=99)$ & \\
\hline $\mathrm{BMI}\left(\mathrm{kg} / \mathrm{m}^{2}\right)$ & $25.53 \pm 3.56$ & $27.01 \pm 4.69$ & 0.09 & $25.85 \pm 4.10$ & $26.30 \pm 3.23$ & 0.65 & $26.04 \pm 3.25$ & $25.96 \pm 4.25$ & 0.94 \\
\hline Waistline $(\mathrm{cm})$ & $87.10 \pm 9.96$ & $89.50 \pm 11.36$ & 0.33 & $87.13 \pm 10.26$ & $89.85 \pm 10.55$ & 0.30 & $87.87 \pm 7.90$ & $87.76 \pm 11.17$ & 0.97 \\
\hline Hipline(cm) & $95.86 \pm 7.75$ & $97.84 \pm 9.57$ & 0.31 & $96.33 \pm 8.70$ & $96.51 \pm 6.49$ & 0.93 & $96.36 \pm 4.43$ & $96.59 \pm 9.22$ & 0.88 \\
\hline Systolic pressure(mmHg) & $122.44 \pm 13.84$ & $129.28 \pm 13.39$ & 0.06 & $123.04 \pm 13.96$ & $131.50 \pm 11.98$ & 0.10 & $121.61 \pm 13.60$ & $124.18 \pm 14.04$ & 0.45 \\
\hline Diastolic pressure(mmHg) & $71.44 \pm 4.04$ & $73.72 \pm 4.86$ & 0.04 & $71.61 \pm 4.24$ & $74.75 \pm 3.81$ & 0.05 & $71.87 \pm 4.71$ & $71.79 \pm 4.18$ & 0.94 \\
\hline Foot examination score & $1.49 \pm 1.62$ & $1.26 \pm 1.18$ & 0.53 & $1.41 \pm 1.51$ & $1.50 \pm 1.54$ & 0.81 & $1.21 \pm 1.35$ & $1.46 \pm 1.53$ & 0.51 \\
\hline$A B \mid(L)$ & $1.10 \pm 0.11$ & $1.12 \pm 0.09$ & 0.36 & $1.10 \pm 0.11$ & $1.15 \pm 0.09$ & 0.07 & $1.06 \pm 0.15$ & $1.12 \pm 0.09$ & 0.05 \\
\hline$A B \mid(R)$ & $1.13 \pm 0.09$ & $1.12 \pm 0.12$ & 0.66 & $1.12 \pm 0.11$ & $1.15 \pm 0.06$ & 0.17 & $1.10 \pm 0.13$ & $1.13 \pm 0.07$ & 0.28 \\
\hline ba-PWV(L)(cm/sec) & $1743.10 \pm 360.03$ & $1817.88 \pm 316.40$ & 0.36 & $1723.99 \pm 302.16$ & $1938.41 \pm 469.54$ & 0.02 & $1725.53 \pm 368.85$ & $1761.38 \pm 348.82$ & 0.71 \\
\hline ba-PWV(R)(cm/sec) & $1760.39 \pm 366.31$ & $1831.88 \pm 305.58$ & 0.38 & $1741.99 \pm 325.82$ & $1937.28 \pm 405.55$ & 0.03 & $1710.88 \pm 383.36$ & $1787.58 \pm 346.15$ & 0.43 \\
\hline $\operatorname{HbA1c(\% )}$ & $7.06 \pm 1.11$ & $6.94 \pm 1.01$ & 0.59 & $7.05 \pm 1.08$ & $6.94 \pm 1.13$ & 0.66 & $7.16 \pm 1.33$ & $6.97 \pm 0.97$ & 0.38 \\
\hline AC sugar(mg/dl) & $137.05 \pm 34.33$ & $136.29 \pm 25.85$ & 0.91 & $137.33 \pm 33.33$ & $134.41 \pm 27.10$ & 0.70 & $139.09 \pm 44.13$ & $135.90 \pm 27.37$ & 0.69 \\
\hline Cholesterol(mg/dl) & $168.97 \pm 34.17$ & $168.03 \pm 34.90$ & 0.89 & $170.01 \pm 34.69$ & $162.09 \pm 31.57$ & 0.32 & $168.97 \pm 37.21$ & $169.10 \pm 33.33$ & 0.98 \\
\hline $\mathrm{TG}(\mathrm{mg} / \mathrm{dl})$ & $116.70 \pm 62.92$ & $145.47 \pm 86.96$ & 0.04 & $118.84 \pm 67.86$ & $149.95 \pm 79.17$ & 0.06 & $139.74 \pm 76.76$ & $119.10 \pm 69.06$ & 0.14 \\
\hline $\mathrm{HDL}(\mathrm{mg} / \mathrm{dl})$ & $50.17 \pm 13.88$ & $44.32 \pm 11.97$ & 0.03 & $49.90 \pm 14.19$ & $42.59 \pm 7.88$ & 0.02 & $47.83 \pm 12.89$ & $49.45 \pm 14.09$ & 0.55 \\
\hline $\mathrm{LDL}(\mathrm{mg} / \mathrm{dl})$ & $96.05 \pm 27.10$ & $91.19 \pm 24.12$ & 0.35 & $95.68 \pm 26.37$ & $90.50 \pm 26.72$ & 0.40 & $98.17 \pm 29.54$ & $93.59 \pm 25.37$ & 0.38 \\
\hline $\mathrm{Cr}(\mathrm{mg} / \mathrm{dl})$ & $0.93 \pm 0.50$ & $0.99 \pm 0.43$ & 0.56 & $0.94 \pm 0.50$ & $0.96 \pm 0.40$ & 0.89 & $0.90 \pm 0.30$ & $0.97 \pm 0.54$ & 0.47 \\
\hline GOT(U/L) & $27.88 \pm 15.69$ & $32.03 \pm 21.16$ & 0.30 & $28.66 \pm 17.61$ & $30.32 \pm 15.62$ & 0.68 & $29.22 \pm 19.24$ & $28.92 \pm 16.99$ & 0.93 \\
\hline GPT(U/L) & $27.66 \pm 15.76$ & $33.59 \pm 31.47$ & 0.30 & $28.76 \pm 20.72$ & $31.09 \pm 21.85$ & 0.63 & $29.79 \pm 19.02$ & $29.30 \pm 21.90$ & 0.91 \\
\hline Microalbumin(mg/day) & $286.79 \pm 982.78$ & $374.99 \pm 1094.05$ & 0.67 & $352.04 \pm 1096.11$ & $95.14 \pm 205.03$ & 0.03 & $244.97 \pm 731.47$ & $339.18 \pm 1111.65$ & 0.67 \\
\hline
\end{tabular}

Values represented as mean \pm SD. $p$-values performed by independent $t$ test $H b A 1 c$ hemoglobin $A 1 c, A C$ sugar fasting blood-glucose level, $T G$ triglyceride, $H D L$ High-density lipoproten,
transaminase, $B M I$ body mass index, $A B l$ ankle brachial index, $b a-P W V$ brachial-ankle pulse wave velocity 


\section{Discussion}

The core of assessment in Chinese medicine is "pattern identification/syndrome differentiation and treatment" based on inspection, listening and smelling examinations, inquiry, and palpation. Inspection is the most important of the four assessments, and tongue assessment is a crucial part of observation. Tongue appearance is a crucial indicator of physiological and pathological changes to the internal organs [19]. Studies have shown that tongue diagnosis plays an important role in clinical prognosis of RA and DM [15, 16, 20-22].

To the best of our knowledge, this is the first attempt to apply TCM tongue diagnosis to the survey of patients with type $2 \mathrm{DM}$. Tongue inspection refers to the shape, color, and fur color, and fur thickness, as well as other characteristics [23]. In patients with DM, buccal alterations can be easily observed with adequate glycemic control. Dry mouth is generally associated with decreased saliva production and is present in 10 to $30 \%$ patients with DM; in these patients, a coated tongue is also observed [24]. In TCM, diabetes-related symptoms are referred to as "Xiaoke", which means increased thirst (or polydipsia), since as long as 2000 years [25]. Furthermore, we show that $47.1 \%$ of patients possessed a coated tongue (i.e., thick fur). According to the TCM theory, tongue fur indicates the Yang organs, especially the digestive system. Thick fur is usually associated with phlegm-dampness and patterns of blood stasis [26]. Thus, understanding and interpreting these tongue manifestations of DM by TCM are important for both in theoretical and clinical applications.

Pulse wave velocity (PWV) is a noninvasive clinical index of arterial stiffness. Arterial pulse wave velocity reflects the stiffness of arteries, and serves as an indicator of atherosclerosis [27, 28]. Arterial stiffness is an agerelated process that is present in numerous diseases, including DM. The PWV of patients with DM is higher than that of healthy subjects [29]. According to previous studies, ba-PWV $\geq 1600 \mathrm{~cm} / \mathrm{sec}$ is an independent risk factor for cardiovascular disease and vascular complications [30]. Here, we observed an average ba-PWV above $1700 \mathrm{~cm} / \mathrm{sec}$ in patients with type $2 \mathrm{DM}$; this implies arterial stiffness.

Tongue manifestations are important features for detecting blood stasis [17]. Our study revealed that the tongue manifestations of blood stasis (i.e., petechiae tongue, bluish tongue, or engorged sublingual collateral vessels) corresponded to higher ba-PWV, particularly for patients with petechiae tongue. Furthermore, we evaluated the relationship between the change of ba-PWV and the number of blood stasis tongue manifestations. The results showed that patients possessing increased blood stasis tongue manifestations had significantly increased mean ba-PWV (78.8 cm/sec; $p=0.037)$. This suggests that patients with type $2 \mathrm{DM}$ have increased blood stasis tongue manifestations that are correlated with severe arterial stiffness.

There were several limitations of our study. First, the sample size was relatively small. Second, we did not enroll healthy controls or patients with type $1 \mathrm{DM}$; this is because most patients with type $1 \mathrm{DM}$ only use conventional medicine (i.e., insulin injection) and do not utilized TCM as a complementary therapy. Therefore, further studies with larger sample sizes, including healthy subjects as well as type 1 and type 2 DM groups, are required to determine the relationship between tongue manifestations and disease. This proposed study can provide a rationale for a wider use of tongue diagnosis in clinical practice.

\section{Conclusion}

Blood stasis of the tongue, particularly petechiae tongue, is associated with arterial stiffness in patients with type 2 DM. Tongue diagnosis is helpful for detecting blood stasis and could serve as a feasible predictor of DM.

\section{Acknowledgments}

The authors would like to thank all of the colleagues who contributed to this study.

\section{Funding}

This study was supported in part by China Medical University Hospital, Taichung Taiwan (DMR-105-094), and in part by Taiwan Ministry of Health and Welfare Clinical Trial and Research Center of Excellence (MOHW105-TDU-B-212-133019) and CMU under the Aim for Top University Plan of the Ministry of Education, Taiwan.

\section{Availability of data and materials}

All the data is contained in the manuscript.

\section{Authors' contributions}

$P C H, J Y C$, and $L C L$ conceived the study. PCH, PYL, and LCL conducted the study. YCH performed the statistical analysis. $\mathrm{PCH}, \mathrm{HHC}$ and $\mathrm{LCL}$ led the writing of the manuscript. All authors commented on the analytic plan and interpretation, and contribution to the editing and final approval of the manuscript.

\section{Competing interests}

All authors declare that they have no conflict of interest.

\section{Consent for publication}

Informed consent documents were obtained for publication of these figures and photographs in the article.

\section{Ethics approval and consent to participate}

This study was approved by the Institutional Review Board of the Changhua Christian Hospital. All participants in the study signed informed consent documents.

\section{Author details}

${ }^{1}$ Graduate Institute of Chinese Medicine, China Medical University, Taichung, Taiwan. 'Department of Chinese Medicine, Changhua Christian Hospital, No.135 Nanxiao St., Changhua, Taiwan. ${ }^{3}$ School of Chinese Medicine, China Medical University, No. 91, Hsueh-Shih Rd., Taichung, Taiwan. ${ }^{4}$ Department of Medical Research, China Medical University Hospital, Taichung, Taiwan.

${ }^{5}$ Department of Computer Science and Engineering, National Sun Yat-sen

University, Kaohsiung, Taiwan. ${ }^{6}$ Department of Healthcare Administration and Medical Informatics, Kaohsiung Medical University, Kaohsiung, Taiwan.

${ }^{7}$ Research Center for Chinese Medicine and Acupuncture, China Medical University, Taichung, Taiwan. ${ }^{8}$ Department of Endocrinology, Changhua Christian Hospital, No.135 Nanxiao St., Changhua, Taiwan. ${ }^{9}$ Graduate Institute 
of Statistical and informational Science, National Changhua University of Education, Changhua, Taiwan.

Received: 30 September 2015 Accepted: 20 August 2016

Published online: 27 August 2016

\section{References}

1. Yang W, Lu J, Weng J, Jia W, Ji L, Xiao J, Shan Z, Liu J, Tian H, Ji Q, et al. Prevalence of diabetes among men and women in China. N Engl J Med. 2010;362(12):1090-101.

2. Engelgau MM, Geiss LS, Saaddine JB, Boyle JP, Benjamin SM, Gregg EW, Tierney EF, Rios-Burrows N, Mokdad AH, Ford ES, et al. The evolving diabetes burden in the United States. Ann Intern Med. 2004;140(11):945-50.

3. Wild S, Roglic G, Green A, Sicree R, King H. Global prevalence of diabetes: estimates for the year 2000 and projections for 2030. Diabetes Care. 2004; 27(5):1047-53.

4. Chen SY, Hsu YM, Lin YJ, Huang YC, Chen CJ, Lin WD, Liao WL, Chen YT, Lin WY, Liu YH, Yang JS, Sheu JC, Tsai FJ. Current concepts regarding developmental mechanisms in diabetic retinopathy in Taiwan. Biomed (Taipei). 2016;6(2):1-8.

5. Jung JH, Tantry US, Gurbel PA, Jeong YH. Current antiplatelet treatment strategy in patients with diabetes mellitus. Diabetes Metab J. 2015;39(2):95-113.

6. Creager MA, Luscher TF, Cosentino F, Beckman JA. Diabetes and vascular disease: pathophysiology, clinical consequences, and medical therapy: Part !. Circulation. 2003;108(12):1527-32.

7. Prenner SB, Chirinos JA. Arterial stiffness in diabetes mellitus. Atherosclerosis. 2015;238(2):370-9.

8. Emerging Risk Factors C, Sarwar N, Gao P, Seshasai SR, Gobin R, Kaptoge S, Di Angelantonio E, Ingelsson E, Lawlor DA, Selvin E, et al. Diabetes mellitus, fasting blood glucose concentration, and risk of vascular disease: a collaborative meta-analysis of 102 prospective studies. Lancet. 2010;375(9733):2215-22.

9. Kaptchuk TJ. Chinese medicine : the web that has no weaver. London: Rider; 2000.

10. Lee JA, Park TY, Lee J, Moon TW, Choi J, Kang BK, Ko MM, Lee MS. Developing indicators of pattern identification in patients with stroke using traditional Korean medicine. BMC Res Notes. 2012;5:136.

11. Park B, You S, Jung J, Lee JA, Yun KJ, Lee MS. Korean studies on blood stasis: an overview. Evid Based Complement Altern Med. 2015;2015:316872.

12. Park YJ, Yang DH, Lee JM, Park YB. Development of a valid and reliable blood stasis questionnaire and its relationship to heart rate variability. Complement Ther Med. 2013;21(6):633-40.

13. Luo $L$, Jiang $Y$. Lin chuang wang she cai se tu jie=Traditional Chinese medicine tonque diagnosis. Zhang hua shi: Luo lun gian, jiang yi wu; 2010.

14. Lo LC, Chen YF, Chen WJ, Cheng TL, Chiang JY. The study on the agreement between automatic tongue diagnosis system and traditional Chinese medicine practitioners. Evid Based Complement Alternat Med. 2012;2012:505063.

15. Liao PY, Hsu PC, Chen JM, Chiang JY, Lo LC. Diabetes with pyogenic liver abscess-A perspective on tongue assessment in traditional Chinese medicine. Complement Ther Med. 2014;22(2):341-8.

16. Lo LC, Chiang JY. Traditional Chinese medicine tongue diagnosis. Changhua city: Lun-Chien lo, John. Y. Chiang; 2010.

17. Lo LC, Chen CY, Chiang JY, Cheng TL, Lin HJ, Chang HH. Tongue diagnosis of traditional Chinese medicine for rheumatoid arthritis. Afr J Tradit Complement Altern Med. 2013;10(5):360-9.

18. Laurent S, Cockcroft J, Van Bortel L, Boutouyrie P, Giannattasio C, Hayoz D, Pannier B, Vlachopoulos C, Wilkinson I, Struijker-Boudier H, et al. Expert consensus document on arterial stiffness: methodological issues and clinical applications. Eur Heart J. 2006;27(21):2588-605.

19. Zheng ZJ, Sharrett AR, Chambless LE, Rosamond WD, Nieto FJ, Sheps DS, Dobs A, Evans GW, Heiss G. Associations of ankle-brachial index with clinical coronary heart disease, stroke and preclinical carotid and popliteal atherosclerosis: the Atherosclerosis Risk in Communities (ARIC) Study. Atherosclerosis. 1997;131(1):115-25.

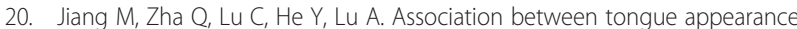
in Traditional Chinese Medicine and effective response in treatment of rheumatoid arthritis. Complement Ther Med. 2011;19(3):115-21.

21. He Y, Lu A, Zha Y, Tsang I. Differential effect on symptoms treated with traditional Chinese medicine and western combination therapy in RA patients. Complement Ther Med. 2008;16(4):206-11.
22. Jiang WY. Therapeutic wisdom in traditional Chinese medicine: a perspective from modern science. Trends Pharmacol Sci. 2005;26(11):558-63.

23. Lo LC, Chiang JY, Cheng TL, Shieh PS. Visual agreement analyses of traditional chinese medicine: a multiple-dimensional scaling approach. Evid Based Complement Alternat Med. 2012;2012:516473.

24. Negrato CA, Tarzia O. Buccal alterations in diabetes mellitus. Diabetol Metabol Syndr. 2010;2:3.

25. Tong $X L$, Dong $L$, Chen $L$, Zhen Z. Treatment of diabetes using traditional Chinese medicine: past, present and future. Am J Chin Med. 2012;40(5):877-86.

26 Anastasi JK, Currie LM, Kim GH. Understanding diagnostic reasoning in TCM practice: tongue diagnosis. Altern Ther Health Med. 2009;15(3):18-28.

27 Laurent S, Boutouyrie P, Asmar R, Gautier I, Laloux B, Guize L, Ducimetiere P, Benetos A. Aortic stiffness is an independent predictor of all-cause and cardiovascular mortality in hypertensive patients. Hypertension. 2001:37(5):1236-41.

28 O'Rourke M. Mechanical principles in arterial disease. Hypertension. 1995;26(1):2-9.

29 Taniwaki H, Kawagishi T, Emoto M, Shoji T, Kanda H, Maekawa K, Nishizawa Y, Morii H. Correlation between the intima-media thickness of the carotid artery and aortic pulse-wave velocity in patients with type 2 diabetes. Vessel wall properties in type 2 diabetes. Diabetes Care. 1999;22(11):1851-7.

30 Ha BK, Kim BG, Kim DH, Lee SI, Jung SM, Park JY, Lee CW, Kim SS, Kim BH, Kim IJ. Relationships between brachial-ankle pulse wave velocity and peripheral neuropathy in type 2 diabetes. Diab Metabol J. 2012;36(6):443-51.

\section{Submit your next manuscript to BioMed Central and we will help you at every step:}

- We accept pre-submission inquiries

- Our selector tool helps you to find the most relevant journal

- We provide round the clock customer support

- Convenient online submission

- Thorough peer review

- Inclusion in PubMed and all major indexing services

- Maximum visibility for your research

Submit your manuscript at www.biomedcentral.com/submit
Biomed Central 